\title{
A Calculation of Spatial Range of Colloidal Silicic Acid Deposited Downstream from the Alkali Front*
}

\author{
Yuichi NIIBORI**, Kazuki IIJIMA***, Naoyuki TAMURA** \\ and Hitoshi MIMURA** \\ ** Dept. of Quantum Science \& Energy Engineering, Tohoku University, \\ 6-6-01-2, Aoramaki, Aza-Aoba, Aoba-ku, Sendai 980-8579 Japan \\ E-mail: yuichi.niibori@jqse.tohoku.ac.jp \\ *** Development Directorate, Japan Atomic Energy Agency (JAEA), \\ 4-33 Muramatsu, Tokai-mura, Naka-gun, 319-1194 Japan
}

\begin{abstract}
A high alkali domain spreads out due to the use of cement materials for the construction of the repository of radioactive wastes. Sudden change of $\mathrm{pH}$ at this alkali front produces colloidal silicic acid (polymeric silicic acid) in addition to the deposition of supersaturated monomeric silicic acid onto the fracture surface of flow-pathway. The colloidal silicic acid also deposits with relatively small rate-constant in the co-presence of solid phase. Once the flow-path surface is covered with the amorphous silica, the surface seriously degrades the sorption behavior of radionuclides (RNs). Therefore, so far, the authors have examined the deposition rates of supersaturated silicic acid. This study summarized the deposition rate-constants defined by the first-order reaction equation under various conditions of co-presence of amorphous silica powder. Then, using the smallest rate-constant $\left(1.0 \times 10^{-12} \mathrm{~m} / \mathrm{s}\right.$ in the co-presence of calcium ions of $\left.1 \mathrm{mM}\right)$ and a simulation code, COLFRAC-MRL, the spatial range of colloidal silicic acid deposited downstream from the alkali front was estimated. The results suggested the clogging caused by the deposition of colloidal silicic acid in flow-path. The altered spatial range in the flow-path was limited to around $30 \mathrm{~m}$ in fracture and to several centimeters in rock matrix.
\end{abstract}

Key words: Radioactive Waste Repository, High pH Plume, Alteration, Colloidal Silicic Acid, Deposition Rate

\section{Introduction}

The cement-based structural materials (e.g., cement grout) are required for the construction of the repository of radioactive wastes located under the groundwater table. Such cement materials would produce high alkali plume ${ }^{(1)-(3)}$, dramatically changing $\mathrm{pH}$ downstream by diluting with the surrounding natural groundwater $(\mathrm{pH} \approx 8)$ as shown in Fig. 1. Hereinafter, such a large change of $\mathrm{pH}$ is referred to as "alkali front", in this study. Since the solubility of silicic acid remarkably increases with $\mathrm{pH}>9^{(4)}{ }^{(5)}$, the change of $\mathrm{pH}$ from e.g., 12 to 8 undergoes a supersaturated condition of silicic acid.

Chida et al. ${ }^{(6),(7)}$ reported that at the alkali front colloidal silicic acid (polymeric silicic acid) was produced even if in the presence of the solid phase, in addition to the deposition of supersaturated monomeric silicic acid. Furthermore, the colloidal silicic acid also deposited, as amorphous silica, with relatively small rate-constant. That is, the range altered by colloidal silicic acid becomes spatially wider than that by supersaturated monomeric

${ }^{*}$ Received 30 Jan., 2012 (№. 12-0058) [DOI: 10.1299/jpes.6.140]

Copyright $\odot 2012$ by JSME 
silicic acid. Since flow-path surface covered with the amorphous silica seriously degrades the sorption behavior of radionuclides ${ }^{(8)}$, the flow rate of groundwater and the deposition rate of supersaturated silicic acid are key parameters to estimate the spatial spread of altered flow-path surface.

This study summarizes the deposition rate-constants of supersaturated silicic acid defined by the first-order reaction equation in the presence of solid phase. Then, using the smallest rate-constant and fluid flow velocity, the spatial range of colloidal silicic acid deposited downstream from the alkali front is estimated. The smallest rate-constant would yield its widest range altered by the supersaturated silicic acid around the repository.

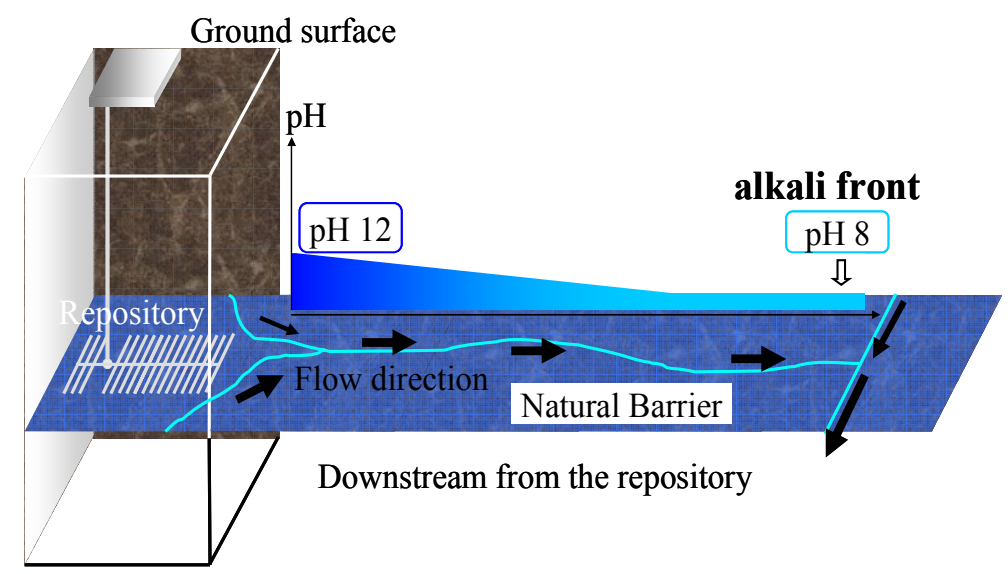

Fig. 1 An illustration of alkali front caused by the use of cement-based structural materials for the repository.

\section{Experimental}

\subsection{Procedures}

So far, the authors have evaluated the deposition rate constants of supersaturated silicic acid $^{(7),(9)-(12)}$. The experimental procedure is as follows:

The silicic acid solution prepared by dissolving water glass $\left(\mathrm{Na}_{2} \mathrm{SiO}_{3}\right.$ solution obtained from Wako Pure Chemical Industries, Ltd.) in distilled ultrapure water was put into the polyethylene vessel with cover (solution volume, $245 \mathrm{ml}$ ) and mechanically stirred with a polypropylene stirrer at $300 \mathrm{rpm}$. (There was no difference between $300 \mathrm{rpm}$ and $400 \mathrm{rpm}$ in estimate of the deposition rates of both soluble silicic acid and colloidal silicic acid). In the vessel, the concentration of silicic acid was given in the range of up to $10 \mathrm{mM}(\mathrm{pH} \approx 12)$. To avoid contact with air, nitrogen was passed through the vessel. A weighed amount of the solid phase (amorphous silica powders within the range of $0.1 \mathrm{~g}$ to $1.0 \mathrm{~g}$ ) was poured into the vessel. Then, the $\mathrm{pH}$ of the solution was set to 8 with an $\mathrm{HNO}_{3}$ solution and a buffer solution mixing MES (2-morpholino-ethanesulfonic acid, monohydrate) and THAM (tris(hydroxymethyl). The temperature was kept constant within $298 \pm 0.5 \mathrm{~K}$.

In the procedure mentioned above, the solid surface is immediately covered with amorphous silica deposited from mainly supersaturated monomeric silicic acid. Then, the colloidal silicic acid gradually deposits on such an altered surface of the solid phase, as shown in Fig. 2(a). However, in an open system such as the near field around the repository, colloidal silicic acid would flow downstream with groundwater, depositing on flow-path surfaces not altered by the deposition of soluble silicic acid, as shown in Fig. 2(b). Therefore, this study tried to contact the colloidal silicic acid more directly with solid phase. That is, after adjusting $\mathrm{pH}$ from 12 to 8 , producing the colloidal silicic acid from supersaturated silicic acid and curing for 12 hours, the solid sample was poured in the solution. This study confirmed through some preparatory experiments that its curing time is enough to apparently stabilize the concentration of colloidal silicic acid in solid phase free system. 


\subsection{Solid Sample}

It is well-known that flow-paths around the repository take the specific surface area larger than at least $10^{4}(1 / \mathrm{m})$. For example, if the flow-path is simply described by a parallel flat board, the specific surface area exceeds $10^{4}$ when the aperture is less than $0.1 \mathrm{~mm}$. In order to simulate such a large specific surface area, the amorphous silica particles were used as solid phase in this study. The solid sample was pure amorphous silica $\left(\mathrm{SiO}_{2} \cdot 0.23 \mathrm{H}_{2} \mathrm{O}{ }^{(13)}\right)$ purchased as Wako-gel C-200 from Wako Pure Chemical Industries, Ltd. and separated to a size fraction of 74-149 $\mu \mathrm{m}$ particle diameters by sieving. Its specific surface area was 450 $\mathrm{m}^{2} / \mathrm{g}$ BET $\left(\mathrm{N}_{2}\right.$ gas).

Furthermore, the amorphous silica as a solid sample simulates a thin layer of amorphous silica on the silicate minerals under the supersaturated conditions of silicic acid. Iler ${ }^{(14)}$ pointed out that the deposition of silicic acid easily forms amorphous layer on the silicate minerals. In fact, Chida et al. ${ }^{(6)}$ examined the apparent solubility of soluble silicic acid in meta-stable state, using various silicate and silica minerals, from a given supersaturated condition. In the results, the solubility of soluble silicic acid controlled by each solid sample agreed with that by amorphous silica particles. In addition, Niibori et al.

${ }^{(8)}$ found (through the sorption experiments of $\mathrm{Eu}$ in the co-presence of soluble silicic acid, colloidal silicic acid and the silica samples) that the apparent solubility of soluble silicic acid slightly dropped in a short time-period when each solid sample of silica was poured in the meta-stable solution of soluble silicic acid and colloidal silicic acid. This suggested that such a contact with solid phase also slightly shifted the equilibrium of soluble and colloidal silicic acids in solution.

Therefore, even if the solid sample is poured in the solution after attaining to a pseudo steady-state of the colloidal silicic acid with no solid phase, the solid surface is slightly altered in a short time-period. However, the degree altered by the initial deposition of supersaturated silicic acid would be different, depending on the experimental procedures. That is, it is predicted that the timing of contact with solid sample in this study, in comparison with the previous procedure, decreases the degree altered on the solid surface.

\section{(a) Previous works}

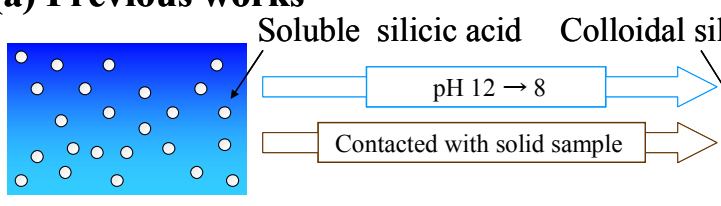

\section{(b) This work}

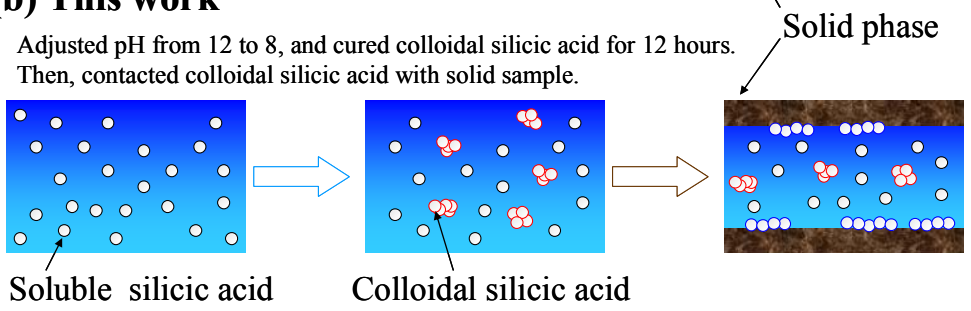

Fig. 2 The difference of the experimental procedures for the contact of the colloidal silicic acid and the solid phase. (In the case (a), the supersaturated soluble silicic acid deposits (covers) on the solid surface (amorphous silica powders), then the colloidal silicic acid gradually deposits on the solid surface. In the case (b), after producing the colloidal silicic acid and curing it for a given time, the colloidal silicic acid contacts the solid phase.)

\subsection{Determination of the Concentrations of Silicic Acid}

In the experiments, the concentrations of both soluble silicic acid and colloidal (polymeric) silicic acid, and the amount of precipitated silicic acid were monitored. Here, soluble silicic acid (monomeric or oligomeric silicic acid) was defined as silicic acid reacting with molybdate reagent and coloring yellow and polymeric silicic acid was defined as silicic acid in liquid phase except for soluble silicic acid. Its total concentration of silicic acid was measured by inductively-coupled plasma atomic emission spectrometry 
(ICP-AES). The concentration of deposited silica was defined as the original concentration of soluble silicic acid minus the total concentration of silicic acid in soluble form and colloidal form, where the original concentration means the concentration of soluble silicic acid prepared in the solution of $\mathrm{pH} 12$.

\section{Experimental Results}

Figure 3 shows the experimental results, where the vertical axis $f$ is the fractions of soluble silicic acid, colloidal form and precipitated silica to the concentration of soluble silicic acid prepared with $\mathrm{pH}=12$. Since the colloidal silicic acid produces before pouring solid phase into the vessel, the initial fraction of the soluble silicic acid becomes less than 1.0 at $t=0$ (the timing when solid sample was poured in the solution). In Fig.3, the "Original concentration of supersaturated silicic acid $(9 \mathrm{mM}$ or $6 \mathrm{mM})$ " means the supersaturated concentration of soluble silicic acid prepared in the solution of $\mathrm{pH} 12$ (i.e., before producing colloidal forms). As mentioned in 2.2, Fig. 3 also showed the shift of equilibrium of soluble silicic acid due to the addition of the solid phase to the solution (i.e., the fraction of soluble silicic acid slightly dropped at $t=0)$. Then, the soluble silicic acid immediately attained to the meta-stable concentration $(=2.2 \mathrm{mM})$ slightly higher than the solubility of silicic acid at $1.9 \mathrm{mM}(\mathrm{pH} 8)^{(4)}$. On the other hand, the decrement rate of colloidal silicic acid strongly depended on the amount of solid phase (the surface area).
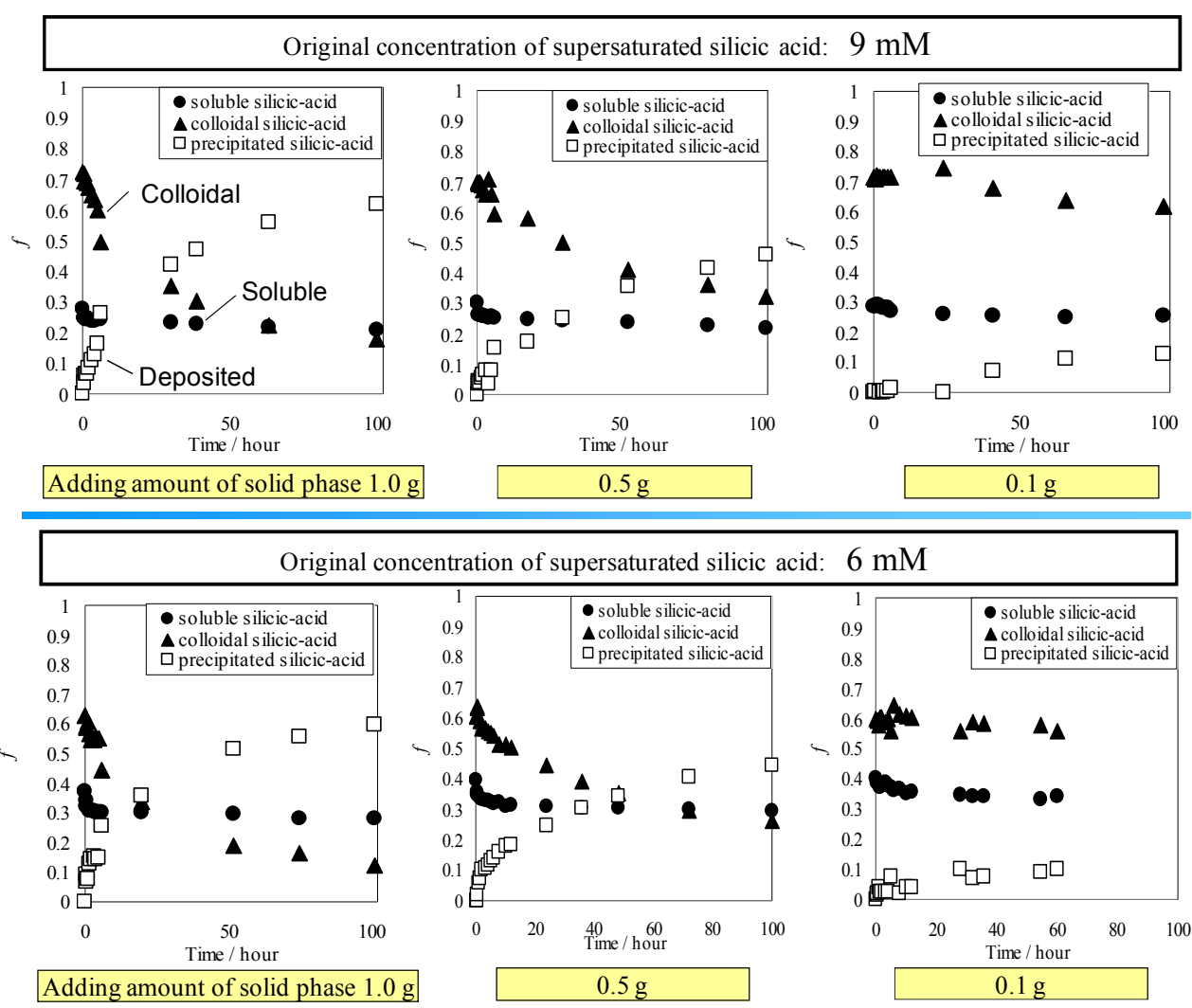

Fig. 3 The changes of the fractions of the soluble silicic acid, the colloidal silicic acid and the deposited (precipitated) silicic acid. (These experiments were carried out in the experimental procedures shown in Fig. 2 (b)).

This study forced on the change of colloidal-silicic acid concentration at this meta-stable state of soluble silicic acid. In this period, the decrease in the amount of colloidal silicic acid is equal to that deposited on the solid surface.

Figure 4 shows the apparent rate-constant $k^{\prime}(1 / \mathrm{s})$ defined by 


$$
-\frac{d f_{c}}{d t}=k^{\prime} f_{c}
$$

where $f_{\mathrm{C}}$ is the fraction of colloidal silicic acid, and $t$ is time (s). $k^{\prime}$ includes the specific surface area. For the fitting, the data of $f_{\mathrm{c}}$ were used in $\left|\mathrm{d} f_{\mathrm{s}} / \mathrm{d} t\right|<0.003(1 / \mathrm{h})$, where $f_{\mathrm{s}}$ is the fraction of soluble silicic acid ${ }^{(6)}$. As shown in Fig. 4, the apparent rate-constant was linear to specific surface area. Therefore, we can obtain the rate-constant $k(\mathrm{~m} / \mathrm{s})$,

$$
k^{\prime}=a k
$$

where $a$ is specific surface area $(1 / \mathrm{m})$ defined in this study by the BET surface area $\left(\mathrm{m}^{2} / \mathrm{g}\right) \times$ weight amount of solid phase $(\mathrm{g}) /$ the solution volume $\left(\mathrm{m}^{3}\right)$. In Fig. 4 , the curing time 0 hour means the experimental result obtained in the previous procedure as shown in Fig. 2 (a). From the results, the values of $k$ were $3.66 \times 10^{-12} \mathrm{~m} / \mathrm{s}$ and $2.50 \times 10^{-12} \mathrm{~m} / \mathrm{s}$ for the curing time of the colloidal silicic acid 0 and 12 hours, respectively. While the difference in the apparent rate-constants may suggest the slight change of the solid surface due to the initial deposition (at $t=0$ ) of supersaturated silicic acid, these values agreed within the range of from $2.50 \times 10^{-12} \mathrm{~m} / \mathrm{s}$ and $3.66 \times 10^{-12}$. Furthermore, the original supersaturated concentration of silicic acid at least in the range less than $10 \mathrm{mM}$ did not affect the rate-constant. In this study, hereinafter, $k$ is referred to as deposition rate constant. Besides, Tamura et al. ${ }^{(12)}$ also examined the apparent rate-constant of colloidal silicic acid (i.e., $3.1 \times 10^{-12} \mathrm{~m} / \mathrm{s}$ ) under the experimental condition of the curing time 0 hour. The value is almost similar to that of this study.

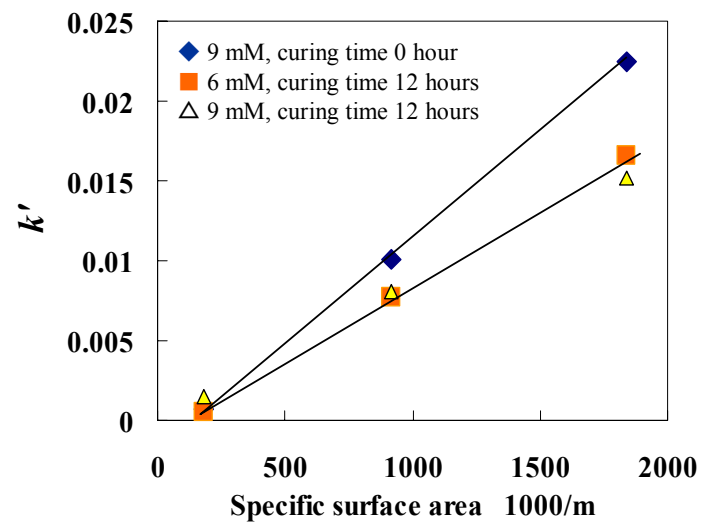

Fig. 4 Relations of the apparent deposition rate-constant, $k^{\prime}(1 / \mathrm{s})$, and the specific surface area. (The curing-time means the time taken before contacting the colloidal silicic acid with the solid phase. The apparent rate-constants, $k^{\prime}$, of "Curing time 0 hour" were obtained through the previous experimental procedures as shown in Fig. 2(a), and the $k^{\prime}$ of "Curing time 12 hours" were done through the procedure shown in Fig. 2(b).)

Table 1 is the summary of the deposition rate-constants estimated in the same way as mentioned above. Here $k_{\mathrm{m}}$ is the deposition rate-constant of soluble silicic acid. As shown in Table 1, the rate-constant of colloidal silicic acid is two-orders of magnitude smaller than that of soluble silicic acid. Furthermore, when $\mathrm{Ca}$ ions are $1 \mathrm{mM}$, the rate-constant is smallest, as shown in Table 1.

On the other hand, Chida et al. ${ }^{(7)}$ reported that, when $\mathrm{Ca}$ ions exceeded $10 \mathrm{mM}$, the colloidal silicic acid instantly precipitates by forming a bridged component of the colloidal silicic acid with $\mathrm{Ca}$ ions. Tamura et al. ${ }^{(11),(12)}$ explained that these behaviors were due to two roles of $\mathrm{Ca}$ ions. That is, one is the surface alteration due to the produce of CSH (Calcium Silicate Hydrate) on the solid surface. Such an alteration would decrease the local surface area, changing the chemical property of the surface. The other is that the remaining $\mathrm{Ca}$ ions in the solution contribute to form the pseudo-colloid. In order to produce the pseudo-colloid large enough to precipitate immediately, $\mathrm{Ca}$ ions need to exceed $10 \mathrm{mM}$ in this system. 
Table 1 Summary of the deposition rate-constant of colloidal silicic acid, $k(\mathrm{~m} / \mathrm{s})$.

\begin{tabular}{|c|c|c|c|c|}
\hline $\begin{array}{l}\text { Initial } \\
\text { colloidal } \\
\text { silicic acid }\end{array}$ & $\begin{array}{l}\text { Ca } \\
\text { ions }\end{array}$ & $\begin{array}{l}k(\mathrm{~m} / \mathrm{s}) \\
\text { Colloidal silicic } \\
\text { acid }\end{array}$ & $\begin{array}{l}k_{\mathrm{m}}(\mathrm{m} / \mathrm{s}) \\
\text { Soluble silicic acid* }\end{array}$ & Remarks \\
\hline free & free & $3.66( \pm 0.57) \times 10^{-12}$ & $5.89( \pm 2.60) \times 10^{-11}$ & Kokubun et al. ${ }^{(9)}$, Tamura et al. ${ }^{(12)}$ \\
\hline free & free & - & $2.10( \pm 0.10) \times 10^{-11}$ & Niibori et al. ${ }^{(10)}$ \\
\hline adjusted & free & $2.50( \pm 0.07) \times 10^{-12}$ & - & This work \\
\hline free & $1 \mathrm{mM}$ & $\begin{array}{l}3.44( \pm 2.44) \times 10^{-12} \\
\text { (The smallest value: } \\
\underline{\left.9.98 \times 10^{-13}\right)}\end{array}$ & $4.29( \pm 0.58) \times 10^{-11}$ & $\begin{array}{l}\text { Evaluated from the initial rate of } \\
\text { the data reported by Chida et al. }{ }^{\left({ }^{7}\right)} \text {. }\end{array}$ \\
\hline
\end{tabular}

" $: k_{\mathrm{m}}(\mathrm{m} / \mathrm{s})$ is the deposition rate-constants of the soluble silicic acid shown for comparing those of colloidal silicic acid.

(Both rate-constants of $k$ and $k_{\mathrm{m}}$ were evaluated from each relation of the apparent rate-constants and the specific surface area as shown in Fig. 4.)

\section{Spatial Range Deposited Downstream}

At JAEA Tokai R\&D Center, Nuclear Fuel Cycle Engineering Laboratories, the authors calculated the spatial range deposited by colloidal silicic acid downstream from an alkali front, using a computation code, COLFRAC-MRL ${ }^{(15)}$ and the smallest rate-constant of the colloidal silicic acid $\left(\approx 1.0 \times 10^{-12} \mathrm{~m} / \mathrm{s}\right)$.

Figure 5 illustrates the calculation system of this study. The code COLFRAC-MRL can treat various cases including the sorption of radionuclide onto colloid and solid surface. This study focused on the transport of colloidal silicic acid. That is, the advection, the dispersion and the deposition rate in a fracture (thin, parallel flat board with aperture $2 b(\mathrm{~m})$ ) were considered in the calculation. Here, the aperture is assumed to be constant. In addition, the diffusion from the flow-path into rock matrix and the deposition rate in the matrix were evaluated. Then, the dimensionless mass balance equation in a fracture is controlled by two dimensionless parameters, Peclet number, $P_{\mathrm{e}}$, and the Damköhler number, $D_{\mathrm{a}}{ }^{(10),(12)}$ :

$$
\begin{gathered}
P_{e}=\frac{z_{1} u_{0}}{D_{e}}, \\
D_{a}=\frac{z_{1} a k}{u_{0}},
\end{gathered}
$$

where $z_{1}$ is the characteristic length (length of flow-path) (m), $u_{0}$ is the fluid flow velocity of groundwater $(\mathrm{m} / \mathrm{s})$ and $D_{\mathrm{e}}$ is the dispersion coefficient $\left(\mathrm{m}^{2} / \mathrm{s}\right)$. In Eq. (4), ak is an apparent rate-constant, corresponding to Eq. (2). Generally, the dispersion coefficient is approximated by $\alpha u_{0}+D_{\mathrm{m}}$, where $\alpha$ is longitudinal dispersivity $(\mathrm{m})$ and $D_{\mathrm{m}}$ is molecular diffusion coefficient $\left(\mathrm{m}^{2} / \mathrm{s}\right)$. As $\alpha u_{0}>>D_{\mathrm{m}}, D_{\mathrm{e}}$ is simply $\alpha u_{0}$. Then, Eq. (3) becomes $P_{\mathrm{e}}=z_{1} / \alpha$. Now considering $z_{1}=100 \mathrm{~m}$ and $\alpha=0.1 z_{1}{ }^{(16)}$, we obtain $P_{\mathrm{e}}=10$. Here, the value of $z_{1}$ was based on a basic scenario of $\mathrm{H} 12$ report ${ }^{(2)}$. Therefore, the critical parameter becomes just only the Damköhler number for the mass transport in a fracture.

Furthermore, in the rock matrix, COLFRAC-MRL can consider the diffusion from the fracture and the deposition rate. Its mass balance equation is controlled by the Peclet number and Damköhler number of rock matrix: $P_{\mathrm{eM}}=\varepsilon z_{1} u_{0} / D_{\mathrm{Ma}}$ and $D_{\mathrm{aM}}=z_{1} a_{\mathrm{M}} k /\left(\varepsilon u_{0}\right)$, where $D_{\mathrm{Ma}}$ is diffusion coefficient, $\varepsilon$ is porosity and $a_{\mathrm{M}}$ is specific surface area in the rock matrix $(1 / \mathrm{m})$. Here, this code assumes $D_{\mathrm{Ma}}, \varepsilon$ and $a_{\mathrm{M}}$ to be constant, respectively. This study defined the dimensionless time, $T\left(=t / t^{*}\right)$, where $t$ is time (s) and $t^{*}$ is the characteristic time $\left(=z_{1} / u_{0}\right)$ ). Therefore, also in the mass balance equation in the rock matrix (i.e., diffusion equation with the rate of one-order reaction), the Peclet number and Damköhler number of rock matrix are 
defined. From H12 Report (JNC, 1999) (except for the deposition rate-constant, $k$, of colloidal silicic acid), this study gave some practical values to these parameters as a basic case. Table 2 is the parameter values set in the calculation.

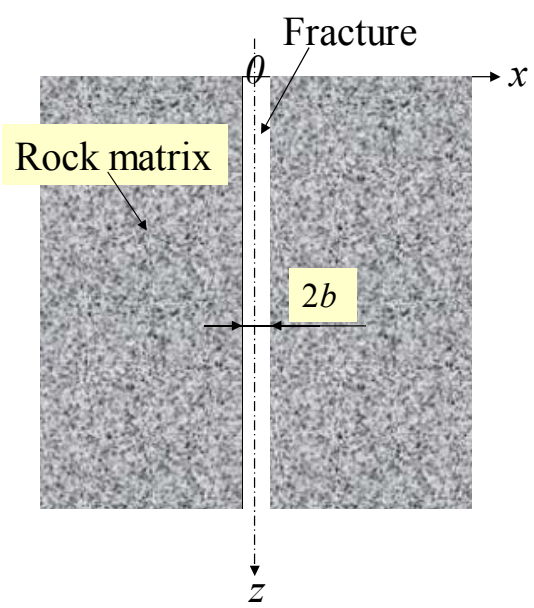

Fig. 5 The calculation system for estimating the concentration distribution of the colloidal silicic acid (In a fracture, one-dimensional mass balance equation of the colloidal silicic acid considering the advection, the dispersion and the deposition rate is used. In addition, the diffusion from the fracture to rock matrix and the deposition rate are considered in the rock matrix.)

As shown in Table 2, the specific surface area, $a$, and the hydraulic conductivity, $K$, are related to the aperture of fracture $b$. Furthermore, the apparent deposition rate-constant, $k^{\prime}$, is also linked to $a$ through Eq. (2). In the calculation of this study, the deposition rate-constant, $k$ (not $k^{\prime}$ ), was fixed to $1.0 \times 10^{-12} \mathrm{~m} / \mathrm{s}$. The Damköhler number of fracture, $D_{\text {a }}$, based on Table 2 and $k=1.0 \times 10^{-12} \mathrm{~m} / \mathrm{s}$ is $8.0\left(P_{\mathrm{e}}=10\right.$ as mentioned above). Then, the Damköhler number and the Peclet number of rock matrix are $D_{\mathrm{aM}}=4.0 \times 10^{4}$ and $P_{\mathrm{eM}}=8.0 \times 10^{5}$, respectively. About the boundary condition, the concentration of colloidal silicic acid fed at $x=0$ and $z=0$ was set to a constant value (Dimensionless concentration=1). The other boundary conditions were described by each normal derivative, $\partial \mathrm{C} / \partial n=0$.

Table 2 Parameters used in the calculation of basic case except for the deposition rate-constant ${ }^{(2)}$.

\begin{tabular}{ll}
\hline Parameter & Value \\
\hline Fracture & \\
characteristic length $\left(z_{1}\right)$ & $100 \mathrm{~m}$ \\
aperture $(2 b)$ & $1.0 \times 10^{-4} \mathrm{~m}$ \\
specific surface area $(a(=1 / \mathrm{b}))$ & $1.0 \times 10^{4} 1 / \mathrm{m}$ \\
gradient of hydraulic head $(\nabla h)$ & -0.01 \\
hydraulic conductivity $\left.\left(K\left(=T_{\mathrm{R}} / 2 b\right)\right)^{*}\right)$ & $2.5 \times 10^{-5} \mathrm{~m} / \mathrm{s}$ \\
flow velocity $(\mathrm{m} / \mathrm{s}) u_{0}(=-K \nabla h)$ & $2.5 \times 10^{-7} \mathrm{~m} / \mathrm{s}$ \\
longitudinal dispersivity $(\alpha)$ & $10 \mathrm{~m}$ \\
dispersion coefficient $\left(D_{\mathrm{e}} \approx \alpha u_{0}\right)$ & $2.5 \times 10^{-6} \mathrm{~m}^{2} / \mathrm{s}$ \\
Rock Matrix & \\
porosity $(\varepsilon)$ & 0.02 \\
diffusion coefficiet $\left(D_{\mathrm{Ma}}\right)$ & $3.0 \times 10^{-12} \mathrm{~m}^{2} / \mathrm{s}$ \\
specific surface area $\left(a_{\mathrm{M}}\left(=10^{2} a\right)\right)$ & $1.0 \times 10^{6} 1 / \mathrm{m}$ \\
\hline$\left.{ }^{*}\right)$ &
\end{tabular}


Figure 6 shows the calculation results of the basic case, where Fig. 6(a) is two-dimensional $(x-z)$ concentration distribution of colloidal silicic acid existing in liquid phase, Fig. 6(b) is the concentration distribution in the fracture with time (year), and Fig. $6(c)$ is the concentration distribution in the rock matrix (at $z=0$ ). Once the flow path surface is covered (altered) with the amorphous silica due to the deposition of silicic acid, it would take more time than several million years in order to crystallize the surface of the solid phase ${ }^{(8)}$, even if the time to attain to the steady state was within around 6 years in the calculation of Figs. 6(b) and 6(c). However, as shown in Fig. 6(b), the deposition area (e.g., assumed in the range of $0.05 \leq C \leq 1.0)$ is limited to around $20 \mathrm{~m}$ from alkali front $(z=0)$. (Since the deposition rate is described by one-order equation with the concentration of colloidal silicic acid, the deposition of colloidal silicic acid appears only in the range of its concentration $>0$.) Furthermore, the deposition range in rock matrix was limited to several centimeters.

Figure 7 shows some examples of the steady state in the concentration distribution of the colloidal silicic acid. Table 3 is the parameter set of each case. These results suggested that the altered spatial range from alkali front is limited to several ten meters. While at the present stage in Japan the total amount of cement-based materials for the construction of the repository is not clarified, this code cannot consider the clogging of the fracture (i.e., the change of fracture aperture) due to the deposition. However, Fig. 7 shows that within at least these ranges the continuous deposition of colloidal silicic acid (described by the deposition rate-constant and the concentration of colloidal silicic acid (in liquid phase)) would lead to the clogging of flow-path (fracture) as reported by Mäder et al. ${ }^{(17)}$, by Soler \& Mäder ${ }^{(18)}$ and by Komatsu et al. ${ }^{(19)}$. Therefore, the radionuclides (RNs) released from the repository move through other flow-paths not altered by the deposition.
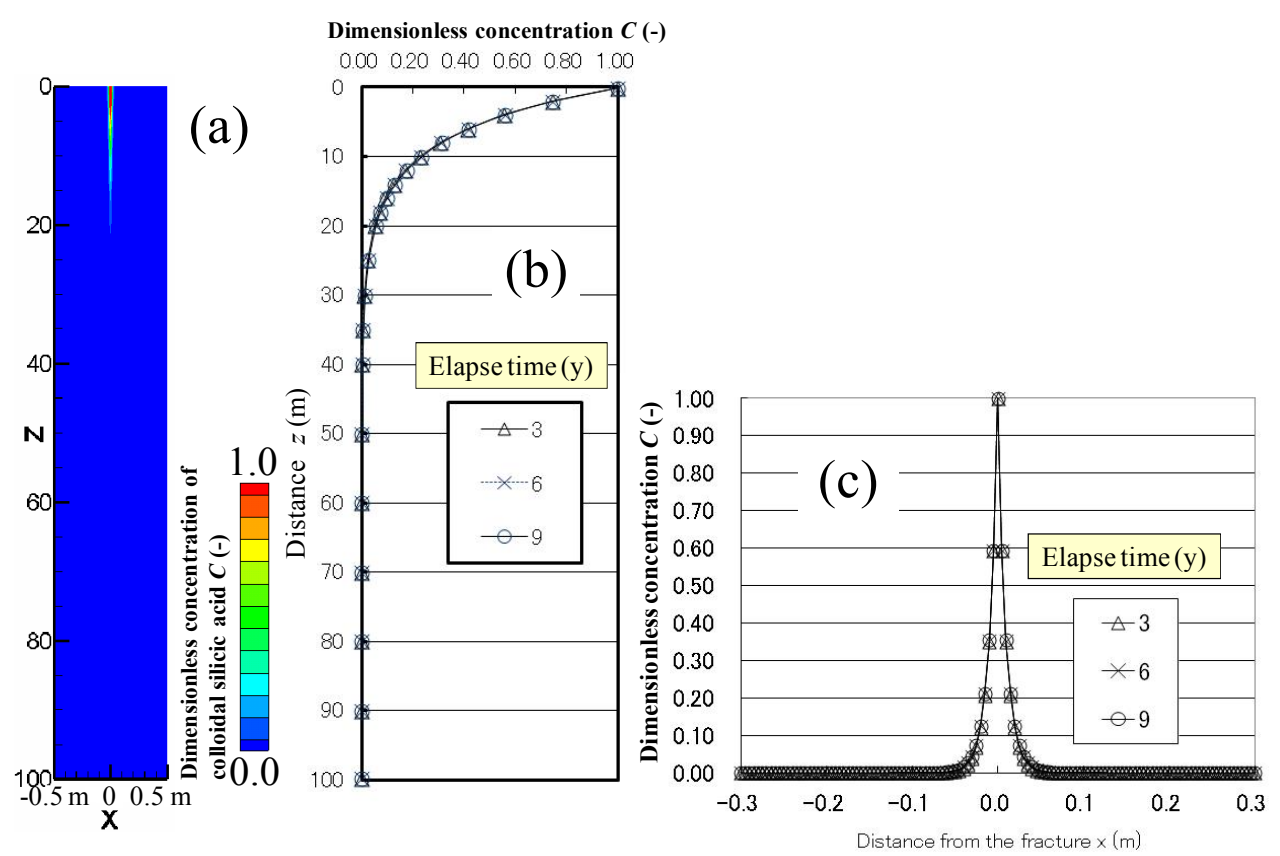

Fig. 6 The calculation results of the basic case shown in Table 2. (The feed-point of colloidal silicic acid (alkali front): $x=0, z=0$. (a): The steady state of the concentration distribution $(x-z)$ of colloidal silicic acid, (b) the concentration change in the fracture, and (c) the concentration change in the rock matrix at $z=0$.) 


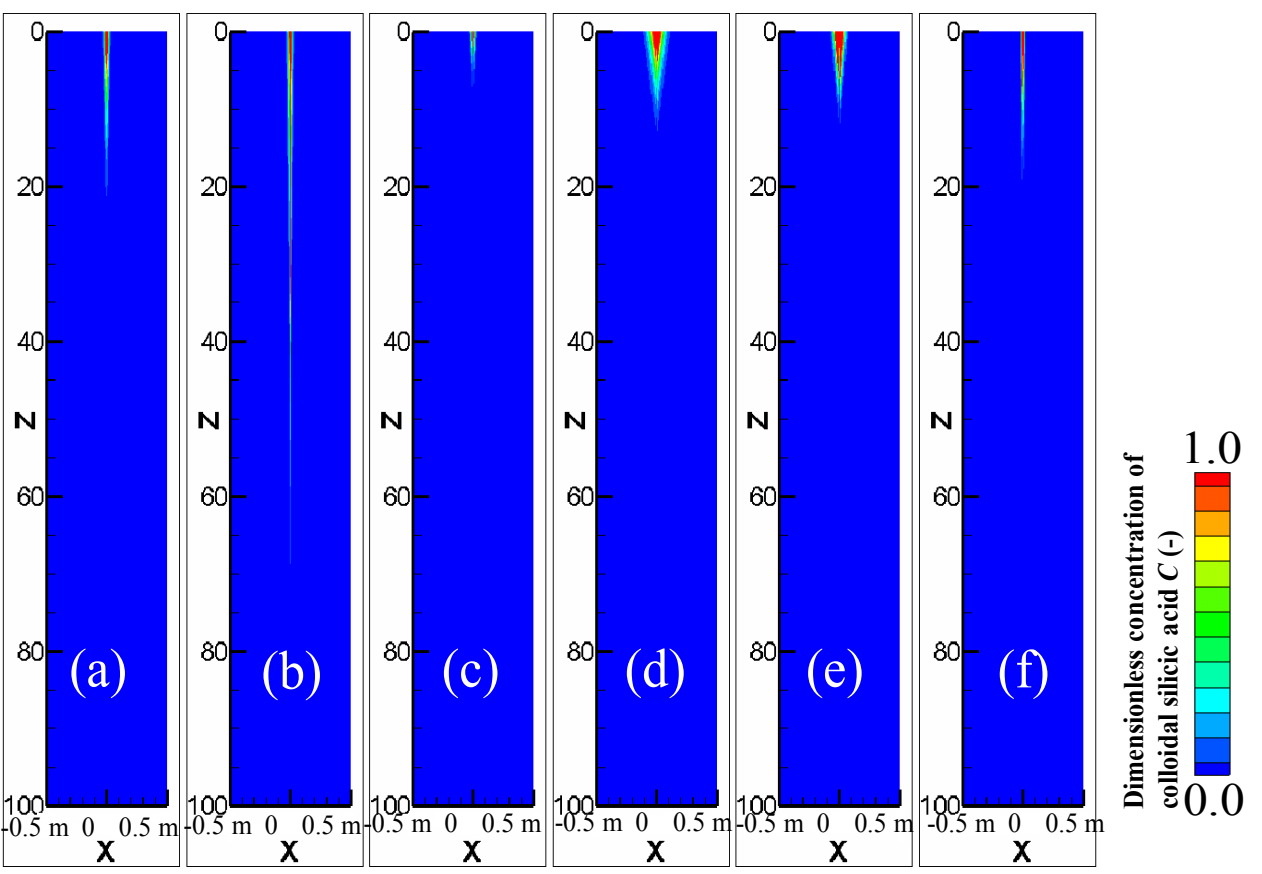

Fig. 7 Two-dimensional concentration distribution of the colloidal silicic acid in the steady state of each case. (The scale bar. of the concentration is the same as shown in Fig. 6(a). Case (a) is the same to the basic case in Fig. 6(a), and the other cases are based on the parameters shown in Table 3.)

Table 3 Parameters of each case of Fig. 7. (Basic case (a) is based on Table 2. Each underline shows the difference from the basic case (a).)

\begin{tabular}{l|llllll}
\hline Parameters & Case (a) & Case (b) & Case (c) & Case (d) & Case (e) & Case (f) \\
\hline $\begin{array}{l}\text { Fracture } \\
\quad \begin{array}{l}\text { Aperture }(2 b)^{*} \\
\text { Rock Matrix }\end{array}\end{array}$ & $1.0 \times 10^{-4} \mathrm{~m}$ & $\underline{2.0 \times 10^{-4} \mathrm{~m}}$ & $\underline{0.5 \times 10^{-4} \mathrm{~m}}$ & $1.0 \times 10^{-4} \mathrm{~m}$ & $1.0 \times 10^{-4} \mathrm{~m}$ & $1.0 \times 10^{-4} \mathrm{~m}$ \\
$\begin{array}{l}\text { Diffusion } \\
\text { coefficiet }\left(D_{\mathrm{Ma}}\right)\end{array}$ & $3.0 \times 10^{-12}$ & $3.0 \times 10^{-12}$ & $3.0 \times 10^{-12}$ & $\underline{3.0 \times 10^{-11}}$ & $\underline{3.0 \times 10^{-11}}$ & $3.0 \times 10^{-12}$ \\
$\begin{array}{l}\text { Specific surface } \\
\text { area }\left(a_{\mathrm{M}}\right)\end{array}$ & $10^{2} a$ & $\mathrm{~m}^{2} / \mathrm{s}$ & $\mathrm{m}^{2} / \mathrm{s}$ & $\underline{\mathrm{m}^{2} / \mathrm{s}}$ & $\underline{\mathrm{m}^{2} / \mathrm{s}}$ & $\mathrm{m}^{2} / \mathrm{s}$ \\
& & $10^{2} a$ & $10^{2} a$ & $10^{2} a$ & $\underline{10^{2} a \times 5}$ & $\underline{10^{2} a \times 5}$ \\
\hline
\end{tabular}

"Through the relations shown in Table 2, the fracture aperture, $2 b$, links the specific surface area of fracture $(a)$, the hydraulic conductivity of fracture $(K)$, the flow velocity of fracture $\left(u_{0}\right)$, the dispersion coefficient $\left(D_{\mathrm{e}} \approx \alpha u_{0}\right)$, and the specific surface area of matrix $\left(a_{\mathrm{M}}\left(=10^{2} a\right)\right)$.

\section{Conclusions}

Since the deposition rate of colloidal silicic acid is smaller than that of soluble silicic acid, the colloidal silicic acid would flow downstream with groundwater, depositing on flow-path surfaces not altered by the deposition of soluble silicic acid. Therefore, this study examined the dynamic behavior of the colloidal silicic acid contacted directly with solid phase. That is, after adjusting $\mathrm{pH}$ from 12 to 8 , producing the colloidal silicic acid from supersaturated silicic acid and curing for 12 hours, the solid sample was poured into the vessel. The results showed that the initial condition of the solid surface did not so affect the apparent rate-constant at least in the range less than $10 \mathrm{mM}$ in supersaturated silicic acid. Furthermore, the apparent rate- constants, $k^{\prime}(1 / \mathrm{s})$, showed good linearity to the specific surface area $(=a(1 / \mathrm{m}))$ under the isotherm condition of $293 \mathrm{~K}$. Therefore, the gradient of $k^{\prime}(1 / \mathrm{s})$ to $a(1 / \mathrm{m})$ can yield the rate-constants $k(\mathrm{~m} / \mathrm{s})$ through $k^{\prime}=a k$.

Through summarizing the deposition rate-constants of supersaturated silicic acid, the smallest value of $k$ was $1.0 \times 10^{-12} \mathrm{~m} / \mathrm{s}$ in the co-presence of calcium ions of $1 \mathrm{mM}$. 
Furthermore, in JAEA, the authors calculated spatial ranges altered by colloidal silicic acid, using a simulation code, COLFRAC-MRL, considering the deposition rate, the advection -dispersion in single fracture, and the diffusion to rock matrix. The practical values of various parameters, such as fracture aperture, surface area of micro pores in rock matrix and so on, except for the deposition rate-constant were quoted from $\mathrm{H} 12$ report of $\mathrm{JNC}^{(2)}$. The calculation results suggested the clogging caused by the deposition of colloidal silicic acid in flow-path. The altered spatial range in the flow-path was limited to around $30 \mathrm{~m}$ in fracture and to several centimeters in rock matrix. Although the deposition of colloidal silicic acid affects the sorption of RNs in rock matrix, such a deposition of silicic acid plays a role of physical barrier by decreasing the permeability of fracture. Therefore, on the whole, the deposition of colloidal silicic acid would lead to the retardation effect of the migration of RNs released from the repository.

\section{Acknowledgments}

This study was supported by Japan Atomic Energy Agency (JAEA) Cooperative Research Scheme (A) on the Nuclear Fuel Cycle for 2007-2009. The authors are grateful to Mr. H. Kokubun (Tohoku University) for his supports to this study.

\section{References}

(1) Atkinson, A., The Time Dependence of $\mathrm{pH}$ within a Repository for Radioactive Waste Disposal, AERE R 11777, UKAEA (1985).

(2) JNC (Japan Nuclear Cycle development institute), H12 Project to Establish the Scientific and Technical Basis for HLW Disposal in Japan, Supporting Report I, Geological Environment in Japan, Chapters V \& VI (1999).

(3) FEPC (Federation of Electric Power Companies of Japan) and JNC, Second TRU progress report, JNC TY1400 2005-013, FEPC TRU-TR2-2005-02 (2005).

(4) Stumm, W. and Morgan, J. J., Aquatic Chemistry (3rd ed.), (1996), John Wiley \& Sons.

(5) Conrad, C. F., Icopini, G. A., Yasuhara, H., Bandstra, J. Z., Brantley, S. L., Heaney, P. J., Modeling the kinetics of silica nanocolloid formation and precipitation on geologically relevant aqueous solution, Geochimica et Cosmochimica, Acta, Vol. 71, (2007), pp. 531-542.

(6) Chida, T., Niibori, Y., Tochiyama, O., and Tanaka, K., Dynamic Behavior of Colloidal Silica in the Presence of Solid Phase, Scientific Basis for Nuclear Waste Management XXVI (Material Research Society), Vol. 757, (2003), pp. 497-502.

(7) Chida, T., Niibori, Y., Tochiyama, O., Mimura, H., Tanaka, K., Deposition rates of polysilicic acid with up to $10^{-3} \mathrm{M}$ calcium ions, Applied Geochemistry, Vol. 22, (2007), pp. 2810-2816.

(8) Niibori, Y., Kasuga, Y., Yoshikawa, H., Tanaka, K., Toshiyama, O., and Mimura, H., An Experimental Approach on the Effect of Rock Alteration on Sorption Behavior, Scientific Basis for Nuclear Waste Management XXIX (Material Research Society), Vol. 932, (2006), pp. 951-958.

(9) Kokubun, H., Niibori1, Y., Iijima, K., and Mimura, H., Deposition Rates of Colloidal Silicic Acid onto the Surface of Silicate Mineral, Proceedings of 16th Pacific Basin Nuclear Conference (16PBNC), No. P16P1154(2008-10), pp. 1-6.

(10) Niibori, Y., Kasuga, Y., Kokubun, H., Iijima, K. and Mimura, H., Dependence of the Dynamic Behavior of Supersaturated Silicic Acid on the Surface Area of the Solid Phase, Scientific Basis for Nuclear Waste Management XXXII, (Material Research Society), Vol. 1124, (2009), pp. 319-324.

(11) Tamura, N., Niibori, Y., Iijima, K., and Mimura, H., Dynamic behavior of silicic acid in the co-presence of the solid phase and $\mathrm{Ca}$ ions, Proceedings of Waste Management (2010-3), No. 10120, pp. 1-10.

(12) Tamura, N., Niibori, Y., and Mimura, H., Deposition Rates of Polymeric Silicic Acid onto the Surface of Silicate Minerals in the Co-presence of Ca Ions, Proceedings of Waste Management (2011-2), No. 11378, pp. 1-9.

(13) Niibori, Y., Kunita, M., Tochiyama, O., and Chida, T., Dissolution Rates of Amorphous 
Silica in Highly Alkaline Solution, Journal of Nuclear Science and Technology, Vol. 37, No. 4, (2000), pp. 349-357.

(14) Iler, R., K., The Chemistry of Silica: Solubility, polymerization, Colloidal and Surface Properties, and Biochemistry, (1979), John Wiley \& Sons.

(15) Ueda, S. and Kuno, Y., Studies on Data Base Management for Nuclide Migration and Improvement of Individual Models, JNC TJ8400 2003-065 (2004).

(16) Ahn, J., Kawasaki, D., and Chambré, P. L., Relationship among Performance of Geologic Repositories, Canister-array Configuration, and Radionuclide Mass in Waste, Nuclear Technology, Vol. 140, (2002), pp. 94-112.

(17) Mäder, U. K., Fierzb, T., Friegc, B., Eikenbergd, J., Rüthid, M., Albinssone, Y., Mörif, A., Ekberge, S. and Stille, P., Interaction of hyperalkaline fluid with fractured rock: Field and laboratory experiments of the HPF project (Grimsel Test Site, Switzerland), Journal of Geochemical Exploration, Vol. 90, (2006), pp. 68-94.

(18) Soler, J. M., Mader, Urs K., Mineralogical alteration and associated permeability changes induced by a high-pH plume: Modeling of a granite core infiltration experiment, Applied Geochemistry, Vol. 22, (2007), pp. 17-29.

(19) Komatsu, K., Usui, H., Kadowaki, J., Niibori, Y., and Mimura, H., Permeability Change with Dissolution and Precipitation Reaction induced by Highly Alkaline Plume in Packed Bed with Amorphous Silica Particles, Proceedings of 16th Pacific Basin Nuclear Conference (16PBNC), (2008-10), No. P16P1167, pp. 1-6. 